
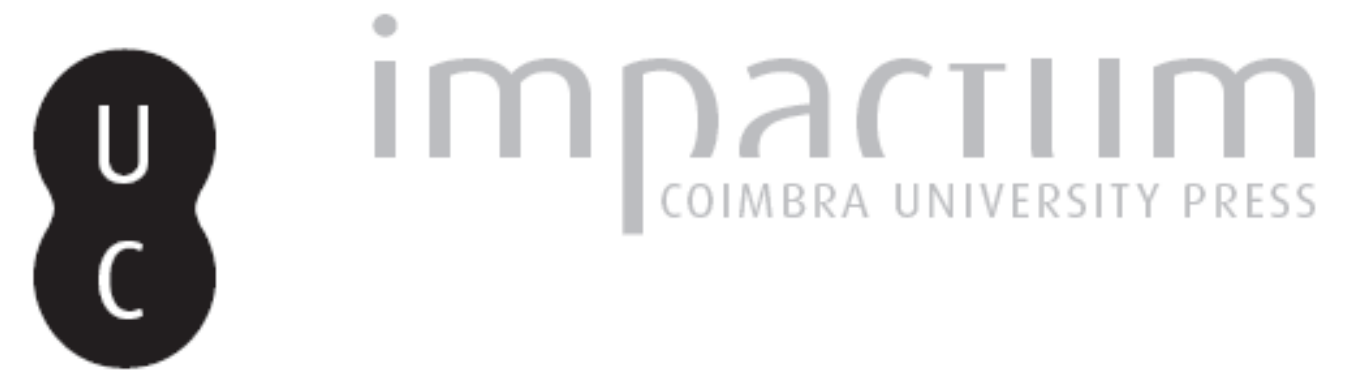

\title{
Heródoto e a guerra: um desafio a Sophrosyne
}

\author{
Autor(es): Silva, Maria de Fátima
}

Publicado por: Centro de História da Universidade de Lisboa

URL persistente:

URI:http://hdl.handle.net/10316.2/23784

DOI:

DOI:http://dx.doi.org/10.14195/0871-9527_19_7

Accessed : $\quad$ 26-Apr-2023 08:29:07

A navegação consulta e descarregamento dos títulos inseridos nas Bibliotecas Digitais UC Digitalis, UC Pombalina e UC Impactum, pressupõem a aceitação plena e sem reservas dos Termos e Condições de Uso destas Bibliotecas Digitais, disponíveis em https://digitalis.uc.pt/pt-pt/termos.

Conforme exposto nos referidos Termos e Condições de Uso, o descarregamento de títulos de acesso restrito requer uma licença válida de autorização devendo o utilizador aceder ao(s) documento(s) a partir de um endereço de IP da instituição detentora da supramencionada licença.

Ao utilizador é apenas permitido o descarregamento para uso pessoal, pelo que o emprego do(s) título(s) descarregado(s) para outro fim, designadamente comercial, carece de autorização do respetivo autor ou editor da obra.

Na medida em que todas as obras da UC Digitalis se encontram protegidas pelo Código do Direito de Autor e Direitos Conexos e demais legislação aplicável, toda a cópia, parcial ou total, deste documento, nos casos em que é legalmente admitida, deverá conter ou fazer-se acompanhar por este aviso.

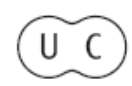



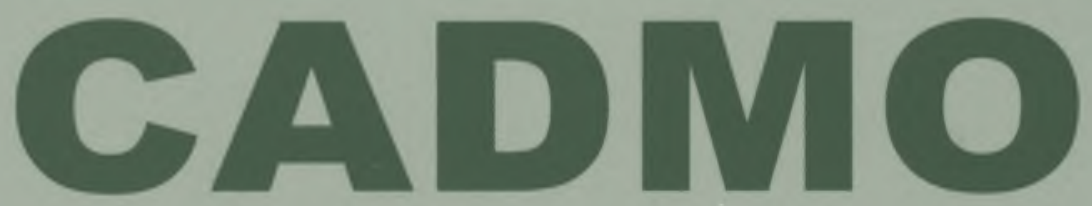

Revista de História Antiga

\author{
Centro de História \\ da Universidade de Lisboa
}

19

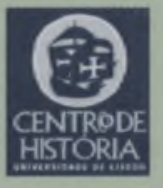

430 =

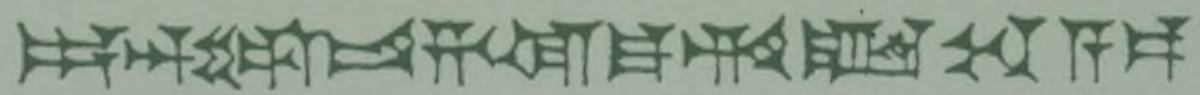

MHNIN AEI $\Delta$ E $\Theta E A ~ \Pi H \Lambda H I A \triangle E \Omega$ 


\title{
HERÓDOTO E A GUERRA. UM DESAFIO A SOPHROSYNE
}

\author{
MARIA DE FÁTIMA SILVA \\ Universidade de Coimbra \\ fanp@ci.uc.pt
}

\section{Resumo}

É sabido que Heródoto usa uma estratégia convencional para narrar campanhas militares; dentro deste pressuposto, iremos analisar os cap. 7. 5-11, que constituem uma espécie de proémio a um momento climático no expansionismo persa, a campanha contra a Grécia. Alguns conceitos são trazidos à discussão, para além de uma estrita avaliação de meios ou estratégias, como se a filosofia dos conflitos bélicos não pudesse deixar de ser recapitulada na iminência de um confronto paradigmático: aquele em que a Ásia e a Europa viveram um choque, mais do que político, cultural. Por isso, a abertura do Livro VII funciona como uma espécie de novo prólogo, onde Heródoto recapitula, num momento crucial, as diversas razões que suscitam, justificam ou condicionam uma guerra.

Palavras-chave: Filosofia da guerra; Guerras Medo-Persas; estratégias militares.

\section{Resumée}

II est bien connu qu'Hérodote répète un modèle conventionnel en faisant le rapport des campagnes militaires; sous ce point de vue, nous allons faire l'analyse des chap. 7. 5-11, qui constituent une espèce d'exorde à un moment suprême de l'expansionisme perse, la campagne contre la Grèce. Quelques valeurs sont mises en discussion, au-delà de l'evaluation 
stricte des moyens ou des stratégies militaires. II devient clair qu'il faut considérer aussi la philosophie de la guerre face à un conflit paradigmatique: celui qui a proportionné, entre l'Europe et l'Asie, un choc plus que politique culturel. C'est pourquoi l'ouverture du Livre VII fonctionne comme une espèce de prologue, où Hérodote fait la récapitulation des différentes causes qui provoquent, justifient ou conditionnent une guerre.

Mots-clés: Philosophie de la guerre; Guerres medo-perses; stratégies militaires.

A longa narrativa das Histórias de Heródoto tem em vista o relato de uma guerra e suas causas, tal como o autor deixa claro no proémio, quando destaca, entre os seus objectivos, abordar "sobretudo a razão por que Gregos e Bárbaros entraram em guerra uns com os outros" (1. 1). Assim, depois de ter passado em revista um vasto rol de campanhas que fizeram dos Persas, um povo belicoso por natureza e tradição, o catalisador de um grande império oriental, Heródoto fixa-se no alvo prometido da sua obra: o conflito entre Bárbaros e Gregos, sobretudo aquele que, depois de confrontos com as comunidades da lónia, trouxe a terreno helénico uma máquina de guerra imponente, sob o comando de Xerxes.

É sabido que o historiador de Halicarnasso usa de uma estratégia convencional na narrativa das sucessivas campanhas de que é relator; e este bloco central nas Histórias não constitui excepção (7. 5-11). A definição das motivações e objectivos do projecto constitui um proémio, mais ou menos extenso, em cada novo relato de guerra ${ }^{(1)}$. Mas sem dúvida, por se tratar de um momento climático no expansionismo persa, a campanha contra a Grécia merece uma ponderação mais extensa e minuciosa(2). Alguns conceitos são trazidos à discussão, para além de uma estrita avaliação de meios ou estratégias, como se a filosofia dos conflitos bélicos não pudesse deixar de ser recapitulada na iminência de um confronto paradigmático: aquele em que a Ásia e a Europa viveram um choque, mais do que político, cultural, e em que os princípios de um equilíbrio universal, estabelecido por barreiras físicas, foi posto em causa. Por isso, a abertura do Livro VII funciona como uma espécie de novo prólogo, onde Heródoto recapitula, num momento crucial, as diversas razões que suscitam, justificam ou condicionam uma guerra. Aplicada esta reflexão a um conflito modelo, torna-se ela mesma universal e paradigmática. 
Para cada momento decisivo na História, Heródoto tende a encontrar um rosto. É dentro desta lógica que os episódios que constituem a sua narrativa têm sido compartimentados em volta de uma sequência régia: Creso, Ciro, Cambises, Dario e Xerxes. Cabe a este último encabeçar a arremetida persa contra a Grécia europeia. Xerxes é, como os restantes condutores do destino humano, aquele a quem compete, em primeiro lugar, assumir o momento fulcral, o da decisão. E Heródoto expande, no comportamento do Grande Rei nesta fase da campanha, alguns factores de personalidade que desvendam o sujeito hesitante, a quem a História reservou uma missão muito acima das suas capacidades pessoais ${ }^{(3)}$. Não é só por uma questão política ou de dramatização literária que Heródoto antecede a campanha de um conselho de guerra; é que o debate que nele tem lugar, dicotómico no radicalismo de um verdadeiro agôn, deixa Xerxes exposto, na decisão final que the cabe, a sucessivas contradições. Sâo responsáveis pelas posições extremadas em discussão Mardónio, primo de Xerxes, defensor entusiasta da campanha, e Artabano, tio do Grande Rei e conse-

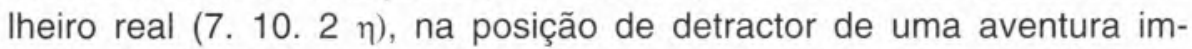
prudente. Trata-se de dois cortesãos muito próximos do monarca, por laços de família e de estatuto, mas a quem a idade, a experiência de vida e o carácter ditam opiniões opostas sobre o projecto. Mais sábio, como é próprio do seu perfil, Artabano sintetiza o contraditório quando reconhece (7. 16. 2): "Sendo dois os planos apresentados aos Persas, um que incitava ao excesso, outro que o refreava - adverso à ideia de que é perigoso insuflar nas consciências o desejo insaciável de possuir mais do que se tem -, (...) tu escolhias o mais arriscado tanto para ti mesmo como para os Persas". Com esta observação, o cortesão faz desta guerra uma confrontação com a sagrada norma de Delfos, medén ágan. O que está em causa é a procura de um difícil equilíbrio entre hybris, "a ambição desenfreada", e o seu contrário, uma desejável sophrosyne, dois conceitos concorrentes no estabelecimento de um cosmos ideal.

$\mathrm{Na}$ medida em que a decisão não depende de uma só vontade, a daquele a quem a ascendência confere o direito de condução dos acontecimentos, mas é o resultado de um cruzamento de mentalidades e de interesses, Heródoto caracteriza também estas duas personagens, que encarnam, certamente, correntes de opinião desencadeadas por uma proposta de guerra. O historiador tem o cuidado de reafirmar que "Xerxes não sentia qualquer impulso" para se lançar

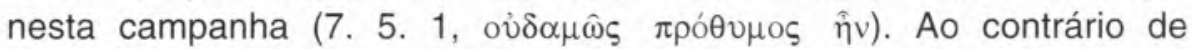


Legrand ${ }^{(4)}$, que acentua a desconfiança que Ihe merece este comentário, entendo que o alheamento do Grande Rei, mais atento aos interesses da Pérsia no Egipto, torna tanto mais sugestivos, dentro da ficção das Histórias, os argumentos a usar para o fazer mudar de ideias. Só com o tempo e a insistência, a persuasão atingiu os seus

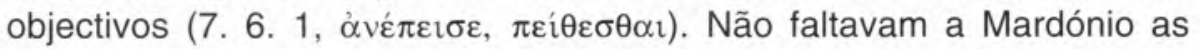
características opostas às que imobilizavam Xerxes: tinha impulso e

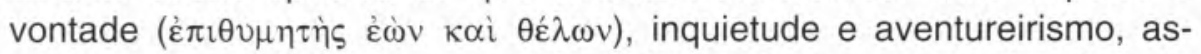
sociados à ambição de conseguir a dignidade de governador da Grécia. Portanto a dinâmica de guerra veio sobretudo do cortesão. Mas outros factores favoreceram este impulso inicial: o natural ascendente

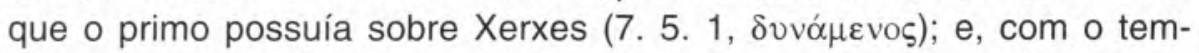
po, a aliança de outras vozes que se the associaram, de Gregos da Tessália e dos Pisistrátidas de Atenas, com outros argumentos ditados por desígnios próprios da intervenção política nas suas cidades ${ }^{(5)}$. Por fim, decisiva foi a interferência de um cresmólogo, que trouxe ao processo o toque motivador do divino (7. 6. 3). Soa, portanto, a ironia a afirmação com que Xerxes, finalmente dobrado a um jogo de influências, se decide a convocar um conselho, "para não parecer que tomei uma decisão sozinho" $(7.8 .2)^{(6)}$. Ora não só o monarca foi arrrastado pelos que o cercavam, como passou a repetir, como seus, os argumentos alheios; ao confrontar o conselho com o seu projecto, tinha de facto tomado já a decisão de avançar.

Dos argumentos usados podemos inferir, no essencial, as motivações que impulsionam uma guerra. As razões aduzidas por Mardónio, primeiro em conversas privadas com o monarca, são depois repetidas em público por Xerxes, embora com uma hierarquização e amplitude diferentes. Mardónio pôs a vingança à frente de todos os outros motivos e defendeu uma desforra dirigida contra Atenas pelos golpes antes

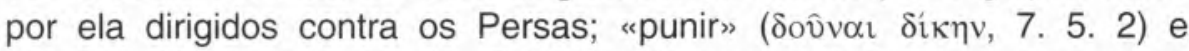

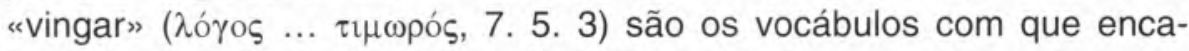
rece a necessidade da guerra. A vingança funciona como uma ocorrência intrínseca ao próprio fluir histórico, como o inevitável reflexo de um acontecimento anterior e também um ponto de partida para reacções futuras. Ou seja, é a vingança ou justiça retributiva o que dá sentido ao nexo histórico. Os acontecimentos não são avulsos, mas sequenciais, dentro de um plano dominado pela retribuição ${ }^{(7)}$.

Sucede-se-lhe, num outro plano de razões políticas, o prestígio que da guerra advém para o monarca e para o poder a que preside. Como grande potência, os Persas poderiam não apenas auferir de 
uma auréola de glória, mas escudar-se nela contra um possível ataque inimigo; a própria fama serve de escudo profiláctico ${ }^{(8)}$. E só por fim, como se a guerra fosse antes de mais um jogo de convivência entre povos, Mardónio sublinha a importância do objecto a conquistar, «a Europa, uma região lindíssima, com árvores de toda a espécie, de uma fertilidade extrema" (7. 5. 3).

Sem desvalorizar a intervenção de $\tau$ $\mu \omega$ pí (uma palavra insistente

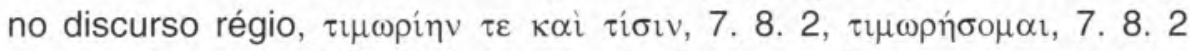
$\beta$, $\tau \mu \omega \rho \eta ́ \sigma \alpha \sigma \theta \alpha$ l, 7. 8. 2) $)^{(9)}$, ou a sedução do território a anexar, o rei centra-se sobretudo no nomos, na atitude do seu povo, que o predispõe à conquista. Trata-se de uma questão cultural, confirmada pela tradição. Desde o seu ascendente mais antigo, Ciro, o fundador do poder persa, que a inquietude expansionista funcionou como um logótipo da corte de Susa (7. 8. 1), inspirada por um deus ou por um destino superior ${ }^{(10)}$. A tradição aparece nas palavras do actual senhor da Pérsia como uma força maior, que se herda e se não discute. São de teor subjectivo os termos que usa, para justificar a submissão ao

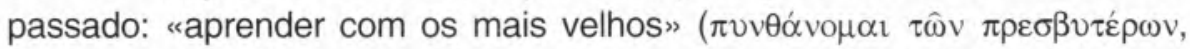
7. 8. $\alpha$ ), "seguir" ou "conformar-se" com comportamentos estabelecidos; ao mesmo tempo que existe entre a tradição e o desejo pessoal de Xerxes uma coincidência, que torna, por enquanto, a sua decisão pacífica. Na essência desta tradição está a ideia de "possuir», fixada no que parece uma legenda da coroa: "preserva o que herdaste e acrescenta-lhe tanto quanto os teus antepassados the acrescentaram». "Somar glória a glória e território a território" define um objectivo político e cultural e coloca o expansionismo, acima da vingança, no centro das causas que desencadeiam a guerra. Esta é a regra que define a natureza de um povo belicoso, que the advém das suas raízes mais profundas e que o nomos, ao longo de séculos, consagrou. Mas perante o conflito iminente contra a Grécia, como limite de um processo, somos levados a tomar consciência da fragilidade deste tipo de comportamento; como lembra Immerwahr ${ }^{(11)}$, "a tradição persa de expansionismo devia conduzir a um máximo de orgulho e de segurança; mas paradoxalmente acarreta incerteza antes da decisão final».

Pela primeira vez, Xerxes traz à discussão sobre a campanha uma avaliação dos meios e estratégias envolvidos. O seu raciocínio, por demais breve, limita-se a afirmar a superioridade persa, em meios técnicos, que lhe permitem sonhar, de acordo com a sugestão de um oráculo, com uma logística avançada (a construção de uma ponte sobre o Helesponto, 7. 8. $\beta$ ) e com o imenso potencial militar, fruto da 
mobilização de inúmeros aliados. O senhor de uma grande potência permite-se um sonho sem limites, num exercício evidente de hybris: alargar as suas fronteiras até ao infinito, de que a Grécia não passa de um mero ponto de partida; dominar todos os povos como seus súbditos; aniquilar toda e qualquer concorrência, pisando aos pés os mais elementares princípios de ética num domínio sistemático sobre todos os povos, sejam eles ou não responsáveis por algum agravo contra os Persas. É claro, no discurso do rei, a prioridade da ambição sobre a vingança e o alheamento dos princípios da justiça.

Depois de aplaudir o sentido das palavras de Xerxes na linha da sua própria posição, Mardónio expande, na intervenção que faz no conselho, uma avaliação do adversário. Este tópico, que tinha escapado de todo a Xerxes, pesaria em favor de uma maior clarividência do cortesão, não fosse ele inspirado na presunção e na arrogância. Incapaz de assimilar a diferença, o primo do rei deprecia-a como debilidade. As interrogações com que introduz esta reflexão - "que volume de tropas? Que potencial económico?», 7. 9. $2 \alpha$-são típicas da mentalidade persa, que tudo quantifica e se impressiona com o número. Mardónio, em resposta, proclama primeiro o seu conhecimento $\left(\dot{\varepsilon} \pi \_\theta \dot{\alpha} \mu \varepsilon \theta \alpha\right)$ da estratégia de combate e da fraqueza de recursos do

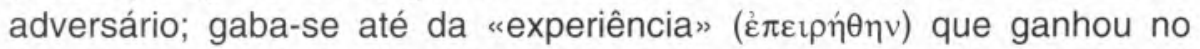
contacto com os lónios. E, no entanto, a sua visão dos Gregos é absolutamente errada. Uma série de termos depreciativos - «envol-

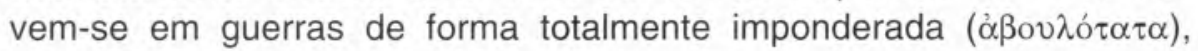

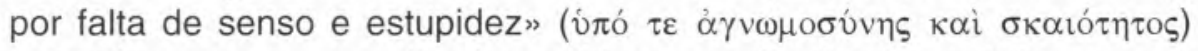
- exprime um preconceito de partida na avaliação dos méritos para o combate. Acrescenta-Ihe a noção de que as guerras em que os Gregos têm prática são internas; e daí infere a sua previsível incapacidade para defrontar um inimigo exterior e poderoso, como acontecera na campanha contra a Macedónia. Heródoto prepara o seu leitor para os que irão ser os tópicos fundamentais nos acontecimentos iminentes ${ }^{(12)}$; é precisamente a natureza estrangeira e a enormidade do invasor o que vai produzir o milagre da união entre os Gregos e estimulá-los a uma resistência extrema. Reprova, sem uma avaliação criteriosa, a preferência do inimigo por espaços estreitos para o combate, um princípio estranho à lógica persa e de cujos méritos Mardónio se não apercebe; sublinha-Ihe o que entende por consequências negativas - "de tal modo que os vencedores sofrem baixas pesadas e os vencidos são totalmente aniquilados", 7. 9. $2 \beta-$, sem se dar conta de que, se aplicada à multidão que constitui as forças persas, a incompa- 
tibilidade é flagrante, como o é também a vantagem que pode constituir para um corpo de tropas limitado; só a evidência dos resultados obtidos nas Termópilas ou em Salamina irá mostrar-Ihe a importância da relação entre o espaço e o potencial de forças, pela crueza das baixas sofridas. Expressiva é também a menção da diplomacia, em tempos de conflito, que Mardónio acusa os Gregos de desconhecerem, mesmo quando o uso de uma só língua, no caso dos conflitos internos, poderia evitar o recurso às armas ${ }^{(13)}$; no entanto, também neste aspecto Salamina vai provar a leviandade persa; quando visitados por um falso fugitivo grego, que traz a notícia da retirada, os Persas tomam à letra uma versão falsa, no justo momento em que a resistência ateniense preparava uma arremetida decisiva (8. 75-76). Nem, por fim, nenhum dos momentos conclusivos do conflito veio provar as vantagens qualitativas do invasor contra qualquer "rasgo de loucura" de um adversário fraco e temeroso. O que agora se chama "experiência" revelou afinal uma profunda ignorância coberta de orgulho.

Artabano assume, no conselho, o contraditório e destrói sistematicamente a argumentação antes aduzida, o que coloca a questão da iniciativa da guerra dentro de outros parâmetros. Os seus argumentos são inspirados num sentido trágico, onde a tradição grega se confronta com a persa ${ }^{14}$. É da "experiência" que vibrava nas últimas palavras de Mardónio (7. 9. $2 \gamma$ ) que Artabano parte para uma nova argumentação, ele que serviu de conselheiro de Dario na campanha contra a Cítia; ora, considerando os dois momentos de uma política expansionista, as semelhanças são flagrantes. O novo orador concentra-se por inteiro em torno do adversário e reduz ao mínimo a relação entre o nomos persa e o resultado do conflito. Na sua opinião, é a natureza do adversário que uma estratégia de guerra deve privilegiar.

Tal como agora Xerxes, também antes Dario projectou, com a mesma subjectividade, a campanha contra os Citas, "na expectativa" ( $\dot{\varepsilon} \lambda \pi \hat{\zeta} \zeta \omega v, 7.10 .2)$ de um êxito, sem se preocupar com as características culturais - o nomadismo em particular - que tornavam o adversário um alvo difícil. Mais sensível à importância de um conhecimento seguro do inimigo, Artabano tentou inutilmente dissuadi-lo. A experiência não deixa dúvidas sobre o desfecho ruinoso de um projecto tão levianamente alinhavado. Sem abatimento, o velho conselheiro não desiste de insistir no conselho, tanto mais oportuno quanto "os Gregos são de longe superiores aos Citas". Aos epítetos reprovadores de Mardónio sobre os Gregos, Artabano substitui, em apreço crescente,

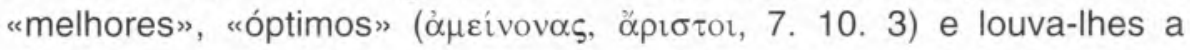


valentia ( $\alpha \ddot{\lambda \kappa \iota \mu о)}$ ). Logo, se algo distingue as duas campanhas é a sua perigosidade ascensional. De acordo com esta excelência, Artabano produz raciocínios hipotéticos sobre a possível vantagem inimiga;

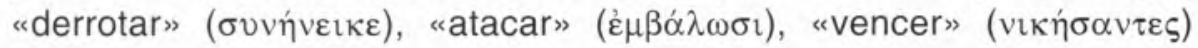
passam a constituir uma outra hipótese, igualmente viável perante uma nova apreciação do adversário. E não se trata de meras suposições (бoфínı oíknínı), mas de uma experiência concreta e colectiva. Por isso, a apreciação de Mardónio é lida como "calúnia", a pior das motivações para um mau conselho, porque esconde, da parte do caluniador, objectivos inconfessáveis, e a quem se deixa influenciar impede um juízo isento e claro.

Se o argumento estratégico de Mardónio é destruído, também o nomos persa, antes lembrado por Xerxes, é objecto de nova ponderação. Mais do que proteger o soberano, a divindade actua sobre a ordem universal, como um factor de equilíbrio, combatendo o que é grande e protegendo o que é pequeno (7. 11. 2 ع). Logo o conhecimento do phthonos divino, o zelo com que os deuses defendem o seu legítimo ascendente sobre a precariedade humana, reduz a vantagem quantitativa que assiste aos Persas a um factor de risco.

Num momento climático da história, mais do que de razões inspiradas na tradição e na experiência, o êxito depende verdadeiramente de um jogo de forças entre tyche, o destino que reina sobre o mundo, e boulê, o conselho ou decisão, com que o homem tem de procurar responder a esse desafio. É, portanto, para o mérito de uma boa decisão que vai o aplauso de um espírito prudente; a clarividência não perde o ascendente, mesmo perante a adversidade; ela é a verdadeira condicionadora do sucesso (7. 10. $2 \delta$ ).

Depois de ouvir todos os argumentos, a Xerxes, como o centralizador deste processo histórico, coube a escolha. As causas que, como um eco de Mardónio, o vemos defender são coerentes com as que, no conjunto das Histórias, justificam os movimentos bélicos. Mas o momento paradigmático que é a campanha contra a Grécia, através da ponderação que Artabano traz ao debate, valoriza como supremo um outro factor: a sensatez. Sobre todas as outras razões, pessoais, políticas e históricas, é ela que derrama a tonalidade suprema da excelência e do sucesso. Apenas, lamentavelmente, o conselheiro, como a voz da razão, está, em Heródoto, condenado ao fracasso, para que a modéstia de espírito dos grandes decisores se apresente como inevitável. Ou não fossem simples mortais aqueles que enfrentam os dilemas que se sucedem na história da Humanidade. 


\section{Notas}

(1) Sobre o assunto, vide H. R. IMMERWAHR, "Aspects of historical causation in Herodotus", TAPhA 87, 1956, 241-280; E. WARDMAN, "Herodotus on the cause of the Greco-Persian war (Herodotus, I, 5)", AJPh 82, 1961, 133-150.

(2) Sobre este episódio, vide F. SOLMSEN, Two crucial decisions in Herodotus, Amsterdam, 1974, 7-12; H. A. GARTNER, "Les rêves de Xerxes et d'Artabane chez Hérodote", Ktema $8,1983,11-18$.

(3) H. R. IMMERWAHR, "Aspects of historical causation in Herodotus", TAPhA 87, 1956, 273, considera Xerxes, na sua hesitação, um caso único na caracterização dos soberanos por Heródoto.

(4) Ph.-E. Legrand, Hérodote. Histoires VII, Paris, Les Belles Lettres, 1951, 26 n. 3. H. R. IMMERWAHR, "The historical action in Herodotus", TAPhA 85, 1954, 30-31, considera este um sinal de abulia típico do carácter de Xerxes, à partida pouco motivado para levar por diante a tradição expansionista dos Persas. A actuação que veio a ter no Conselho significa o percurso feito pelo rei sob diferentes pressões.

(5) Interesses especificos na Grécia tornavam a intervenção do Grande Rei apetecida. Em dificuldades para se imporem na Tessália como soberanos, os descendentes de Alevas, uma familia com pergaminhos aristocráticos descendente do fundador mítico da região, apelavam ao apoio estrangeiro. Do mesmo modo agiam os descendentes de Hípias, tirano de Atenas, com vista ao retorno a um poder que as tendências democráticas da cidade ameaçavam. Sobre o assunto, vide C. SCHRADER, Heródoto. Histórias VII, Madrid, Gredos, 1985, 27-28.

(6) É, de resto, sugestiva a forma verbal, passiva, com que Heródoto assinala o desfecho

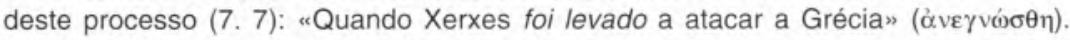

(7) Sobre o tema da vingança em Heródoto, vide P. DEMONT, "Secours et vengeance:

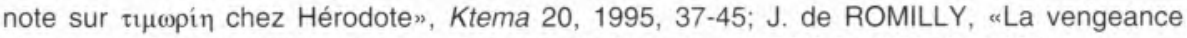
comme explication historique dans l'oeuvre d'Hérodote", REG 84, 1971, 314-337.

(8) Do mesmo modo que os Lídios de Creso atacam o poder emergente da Pérsia (1. 46. 1), ou Esparta o de Atenas (5. 91. 1).

(9) No seu discurso final no conselho, Xerxes repete com veemência este mesmo argumento, como também o da profilaxia de um ataque antecipado, aliados ao factor tradição, que o coloca na linha dos seus antepassados (7, 11, 2-4).

(10) Sobre a relação entre divindade e nomos no discurso de Xerxes, vide J. A. S. EVANS, "Despotes nomos", Athenaeum 43/1-2, 1965, 146-147.

(11) H. R. IMMERWAHR, "The historical action in Herodotus", TAPhA 85, 1954, 41.

(12) Também Ésquilo, nos Persas 230-244, caracteriza a resistência grega num diálogo entre Atossa e os conselheiros, antes de serem conhecidas as notícias sobre o desfecho da invasão comandada por Xerxes.

(13) Para além de uma possível intromissão da opinião de Heródoto, numa espécie de apelo ao entendimento pacífico entre os Gregos, esta observação parece também expressiva de alguma inconsequência na apreciação persa do inimigo.

(14) Cf. J. A. S. EVANS, "The dream of Xerxes and the nomoi of the Persians", CJ 57, $1961,109$. 